\title{
Assessment of cardiac variables using a new electrocardiography lead system in horses
}

\author{
Worakij Cherdchutham, Kanoklada Koomgun, Suchanan Singtoniwet, Napattra Wongsutthawart, \\ Napass Nontakanun, Wipasitnee Wanmad and Soontaree Petchdee $\mathbb{D}$ \\ Department of Large Animal and Wildlife Clinical Sciences, Faculty of Veterinary Medicine, Kasetsart University,
Kamphaeng Saen Campus 73140, Thailand. \\ Corresponding author: Soontaree Petchdee, e-mail: fvetstr@ku.ac.th \\ Co-authors: WC: fvetwkc@ku.ac.th, KK: kanoklada.k@ku.th, SS: suchanan.sin@ku.th, NW: napattra.wo@ku.th, \\ NN: napass.n@ku.th, WW: wipasitnee.w@ku.th \\ Received: 13-01-2020, Accepted: 13-05-2020, Published online: 29-06-2020
}

doi: www.doi.org/10.14202/vetworld.2020.1229-1233 How to cite this article: Cherdchutham W, Koomgun K, Singtoniwet S, Wongsutthawart N, Nontakanun N, Wanmad W, Petchdee S (2020) Assessment of cardiac variables using a new electrocardiography lead system in horses, Veterinary World, 13(6): 1229-1233.

\begin{abstract}
Aim: The objective of this study was to assess a new lead system method to improve electrocardiographic measurement in horses.

Materials and Methods: Twenty-two horses with an average age of $8.8 \pm 0.8$ years were enrolled in this study. Horses were divided into two groups, consisting of a control group $(\mathrm{n}=11)$ and athlete group $(\mathrm{n}=11)$. Electrocardiography (ECG) and echocardiography were performed to provide information on the structure and function of the heart. Two lead systems, base apex and modified precordial leads, were used for the electrocardiogram to assess the cardiac electrophysiological functions.

Results: PR interval, QT interval, and QRS-T angle presented significant differences between the control and athlete groups when the modified precordial lead system was used. However, significant variations in the mean electrical axis were found when the base apex lead system was used. The modified precordial lead system resulted in more significant differences in cardiac electrophysiological parameters than the base apex lead system. In the athlete group, echocardiography showed cardiac adaptations such as increases in the left atrial and left ventricular dimensions and stroke volume and a decrease in heart rate in response to exercise and training. The observed differences in cardiac morphology and function between groups suggested differences in health performance in the athlete group.
\end{abstract}

Conclusion: These data provided the first evidence that the modified precordial lead system improved statistical variation in ECG recording and provided the most reliable method for health screening in horses.

Keywords: echocardiography, electrocardiography, horse, non-invasive cardiac evaluation.

\section{Introduction}

It has been widely shown that exercise training improves health outcomes, such as reducing the risk of cardiac diseases and has been shown to promote many health benefits [1]. However, sudden cardiac death and cardiovascular abnormalities are considered to occur frequently in both athlete and non-athlete populations [2-4]. In athlete horses, an unexplained sudden cardiac death has increased over the past 5 years [5]. Cardiovascular investigation is recommended to perform as an important component of health screening before participating in sport activities [6]. Electrocardiography (ECG) measurement is an important tool to assess the diagnosis of arrhythmias and is a gold standard for the clinical examination of electrical disturbances in horses [7,8]. Many studies have been reported to investigate the cardiac electrophysiological response in horses [9-13]. Equine ECG lead systems

Copyright: Cherdchutham, et al. Open Access. This article is distributed under the terms of the Creative Commons Attribution 4.0 International License (http://creativecommons.org/licenses/ by/4.0/), which permits unrestricted use, distribution, and reproduction in any medium, provided you give appropriate credit to the original author(s) and the source, provide a link to the Creative Commons license, and indicate if changes were made. The Creative Commons Public Domain Dedication waiver (http:// creativecommons.org/publicdomain/zero/1.0/) applies to the data made available in this article, unless otherwise stated. have been developed to obtain a clear ECG recording using different positions of the electrodes. Several lead systems were suggested to be useful for horses and other animals to diagnose cardiac electrophysiological problems [14]. However, there are few data available to evaluate the cardiac electrical function of the horse.

ECG and echocardiography measurements might be useful tools to assess the cardiac functions in the horses. In this present study, the precordial lead position on the horse was modified to verify the sensitivity of the detection of electrocardiographic variations in horses.

The objective of this study was to assess a new lead system method to improve electrocardiographic measurement in horses. We hypothesized that a modified precordial lead system can be used to determine a more appropriate method for cardiac electrophysiological property assessment in horses. The application of this new lead system method among horses might be contributed to improve the electrophysiological measurement of the horses.

\section{Materials and Methods}

Ethical approval

The study was approved by the Ethical Committee for Animal Experiments, Kasetsart University, Thailand (ACKU62-VET-061). 


\section{Study location and period}

The study performed at Ratchaburi Riding Club and Faculty of Veterinary Medicine, Kasetsart University, Kamphaeng Saen campus from March to June 2019.

\section{Animals}

Six females and 16 males Thai native crossbred horses aged $8.8 \pm 0.8$ years and weighing $304.7 \pm 18.2$ $\mathrm{kg}$ were used for this study. The exclusion criteria were the presence of any health problems such as cardiac arrhythmias and structural heart diseases. Horses were assigned into two groups, the control group and the athlete group. All parameters were recorded continuously for further analysis using a blinded assessment.

\section{ECG measurements}

Non-invasive cardiac electrophysiological measurements were performed on 22 horses using a 12-channel ECG recording device (Kent, Japan). The ECGs were recorded at $25 \mathrm{~mm} / \mathrm{s}$ paper speed with a sensitivity of $1 \mathrm{~cm} / \mathrm{mV}$. Six electrodes were placed on the skin with alligator clips to provide the 1 min-ECGs recordings without chemical restraint. Two ECG lead systems were used on each horse (Figure-1). A 1-min ECGs were recorded using each lead system (Figure-2), and the ECG parameters, such as P-wave duration and amplitude, PR interval, QRS duration and amplitude,
QT interval, T-wave morphology, QRS-T angle, and mean electrical axis (MEA), were manually analyzed under the supervision of an experienced cardiologist. The heart MEA was calculated using Einthoven's triangle as a reference. T-wave morphology was divided into three patterns; positive, negative, and biphasic.

\section{Cardiac function evaluations}

Transthoracic echocardiography was performed on resting horses to rule out the cardiac pathology and to evaluate the heart contractility functions. Echocardiographic examination was performed on an unsedated horse in standing position by one experienced cardiologist using a portable ultrasound system (Mindray, China). An echocardiogram with $4.0 \mathrm{MHz}$ frequency transducer was used to obtain the images from the right and left sides of the thorax of the horse. Echocardiographic images were captured and stored for offline analysis. All measurements were the mean for three consecutive cardiac cycles. Left ventricular

Table-1: Characteristics of horses.

\begin{tabular}{lcc}
\hline Horse characteristic & Control & Athlete \\
\hline Gender & Female (6) & Female (1) \\
& Male (5) & Male (10) \\
Age (years) & $10.4 \pm 1.6$ & $7.5 \pm 0.7$ \\
Weight $(\mathrm{kg})$ & $265.0 \pm 23.7$ & $309.5 \pm 17.7$ \\
\hline
\end{tabular}

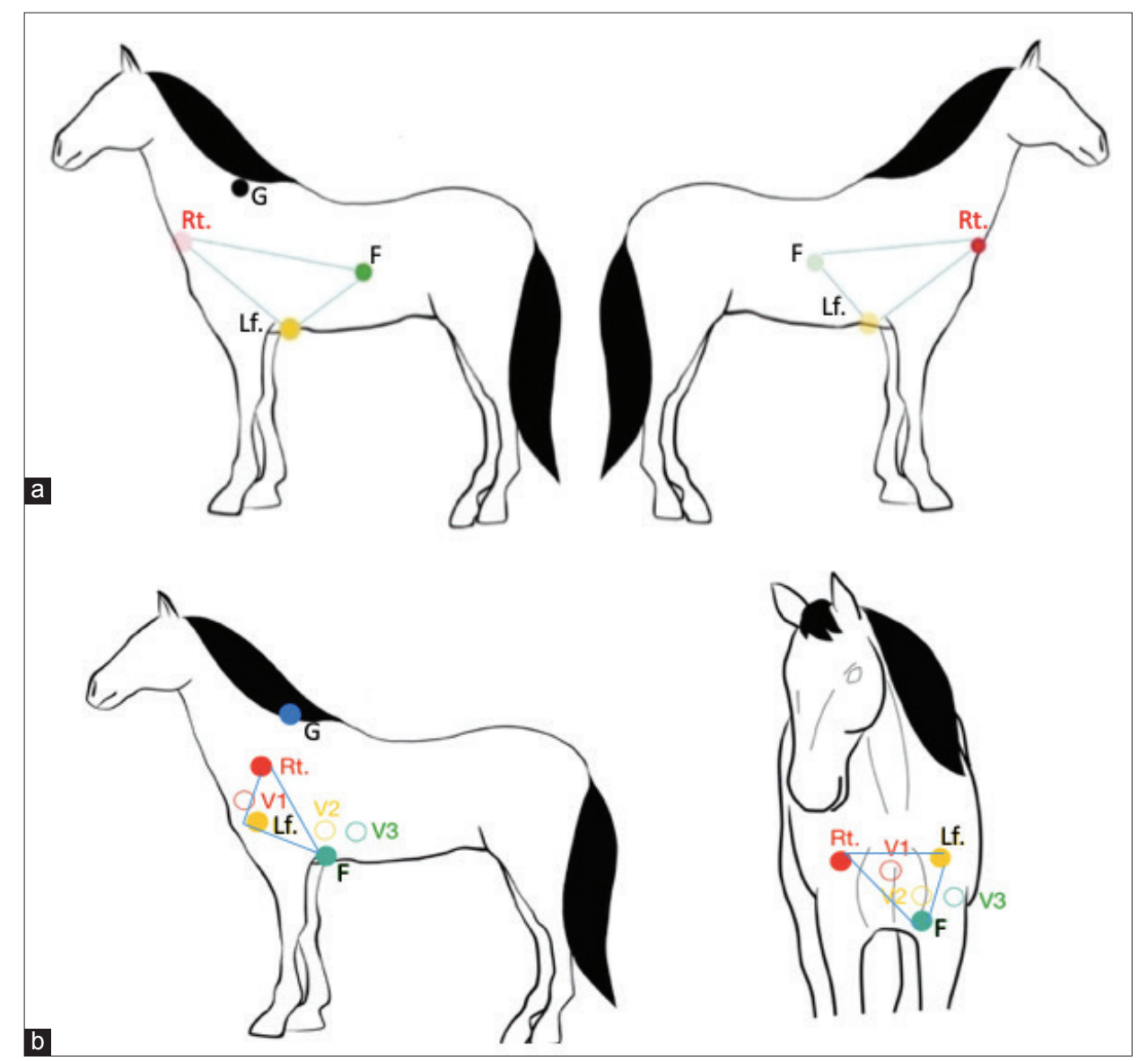

Figure-1: Two electrocardiography lead systems; base apex (a) and modified precordial leads (b), circle represented position of the electrodes; Rt, Lf, F, indicated locations of electrodes for the base apex leads and V1, V2, and V3 for the modified precordial leads, $\mathrm{G}$ represented ground electrode. 

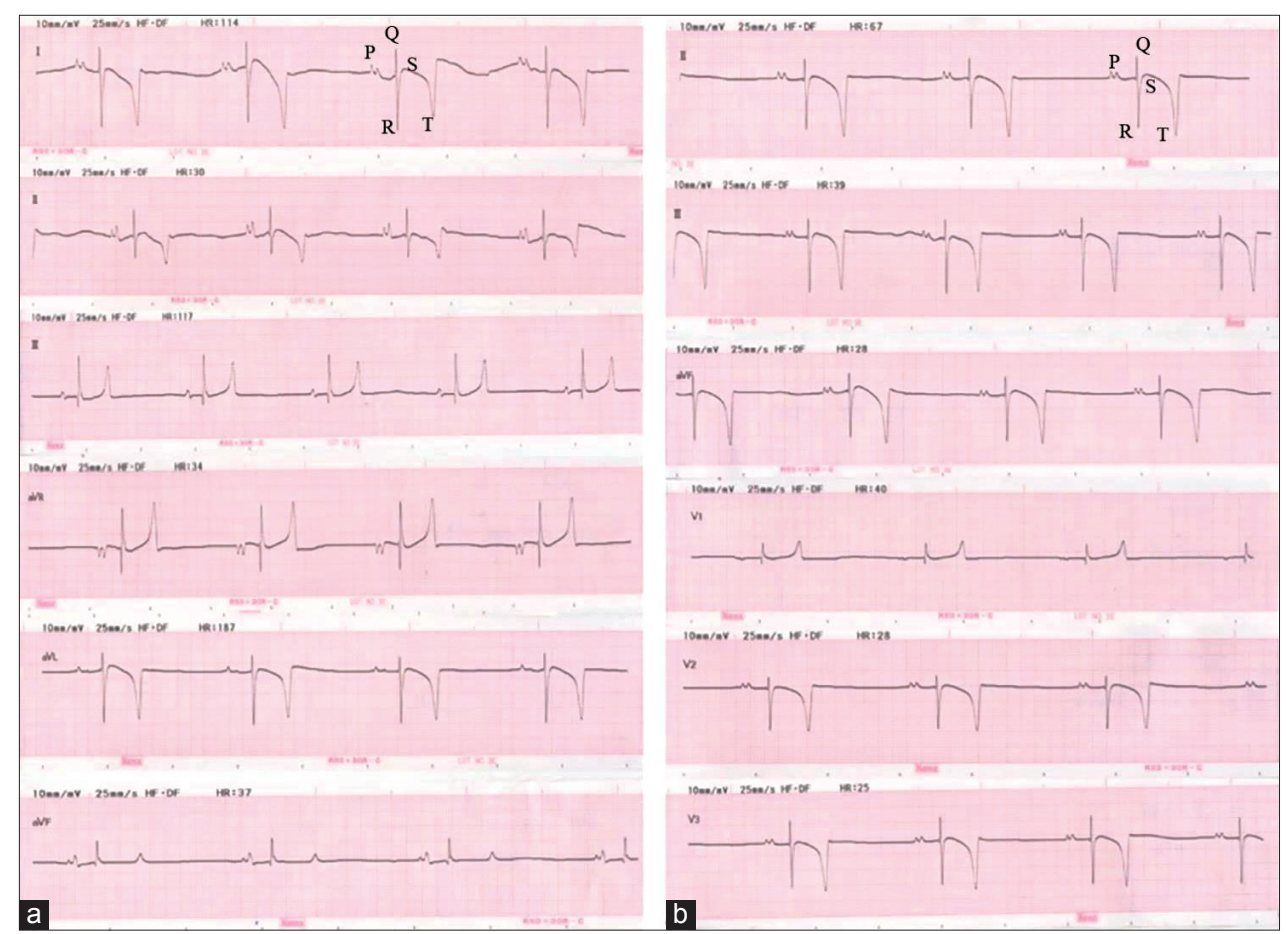

Figure-2: A section of base apex (a) and modified precordial lead (b), Electrocardiography signal such as $P, Q, R, S$, and $\mathrm{T}$ wave were obtained from the recording.

Table-2: Electrocardiography measurements.

\begin{tabular}{|c|c|c|c|c|}
\hline \multirow[t]{2}{*}{ Lead systen } & & \multicolumn{3}{|c|}{ Base apex } \\
\hline & \multicolumn{4}{|c|}{ Control } \\
\hline \multicolumn{2}{|l|}{$\mathrm{P}(\mathrm{ms})$} & & $1 \pm 0.01$ & 0 \\
\hline \multicolumn{2}{|l|}{$P(m V)$} & & $22 \pm 0.02$ & 0 \\
\hline \multicolumn{2}{|l|}{$\mathrm{PR}(\mathrm{ms})$} & & $8 \pm 0.02$ & \\
\hline \multicolumn{2}{|l|}{ QRS (ms) } & & $0 \pm 0.01$ & \\
\hline \multicolumn{2}{|l|}{$\mathrm{R}(\mathrm{mV})$} & & $59 \pm 0.10$ & \\
\hline \multicolumn{2}{|c|}{ QT (ms) } & & $\pm 0.01 * * *$ & 0.5 \\
\hline \multicolumn{2}{|c|}{ T (Neg, Pos, Biphasic) } & & Biphasic $=7$ & $\mathrm{Neg}=$ \\
\hline \multicolumn{2}{|c|}{ QRS-T angle } & & $59 \pm 0.85$ & \\
\hline \multicolumn{5}{|c|}{$\begin{array}{l}\text { Data represented as mean } \pm \text { SEM, } * p<0.05 \text { compared with } \\
* * * p<0.0001 \text { compared with control group }\end{array}$} \\
\hline \multicolumn{5}{|c|}{$\begin{array}{l}\text { Table-3: Coefficient of determination }\left(\mathrm{R}^{2}\right) \text { between base } \\
\text { apex and modified precordial lead system. }\end{array}$} \\
\hline \multirow[t]{2}{*}{ Variables } & \multicolumn{4}{|c|}{ Coefficient of determination $\left(R^{2}\right)$} \\
\hline & \multicolumn{2}{|c|}{ Base apex } & \multicolumn{2}{|c|}{ Modified precordial } \\
\hline$P(\mathrm{~ms})$ & \multicolumn{2}{|c|}{0.0003} & \multicolumn{2}{|c|}{0.0408} \\
\hline$P(m V)$ & \multicolumn{2}{|c|}{0.0216} & \multicolumn{2}{|c|}{0.0016} \\
\hline PR (ms) & \multicolumn{2}{|c|}{0.0192} & \multicolumn{2}{|c|}{0.0107} \\
\hline QRS (ms) & \multicolumn{2}{|c|}{0.0263} & \multicolumn{2}{|c|}{0.2707} \\
\hline $\mathrm{R}(\mathrm{mV})$ & \multicolumn{2}{|c|}{0.6691} & \multicolumn{2}{|c|}{0.1042} \\
\hline QT (ms) & \multicolumn{2}{|c|}{0.6691} & \multicolumn{2}{|c|}{0.5059} \\
\hline
\end{tabular}

wall structure was calculated by measuring the images from standard two-dimensional plane and left ventricular systolic function was calculated from the M-mode echocardiography (Figure-3).

\section{Statistical analysis}

All data are showed as mean \pm standard error of the mean (mean \pm SEM). Statistical analysis was performed using unpaired t-test (GraphPad Prism software version 5). $\mathrm{p}=0.05$ or less was indicated for

statistical significance. The coefficient of determination $\left(R^{2}\right)$ is calculated to analyze the variation of ECG parameters between the two leads system.

\section{Results \\ General characteristic}

All 22 horses (aged $8.8 \pm 0.8$ years, and weighing $304.7 \pm 18.2 \mathrm{~kg}$ ) completed the study without any complications. The characteristics of the study population are summarized in Table-1. There was no statistical difference between groups concerning mean age and body weight ( $\mathrm{p}=0.11$ and $\mathrm{p}=0.15$, respectively). There were significant differences between the control and athlete horses in PR interval, QT interval, and QRS-T angle obtained by modified precordial leads and QT interval differences obtained by base apex lead. Several morphologies of the T wave were observed, and the biphasic configuration was generally presented in this study. The results of the analysis of ECG parameters are shown in Table-2. Table-3 represents a statistical measurement of ECG variations from the 

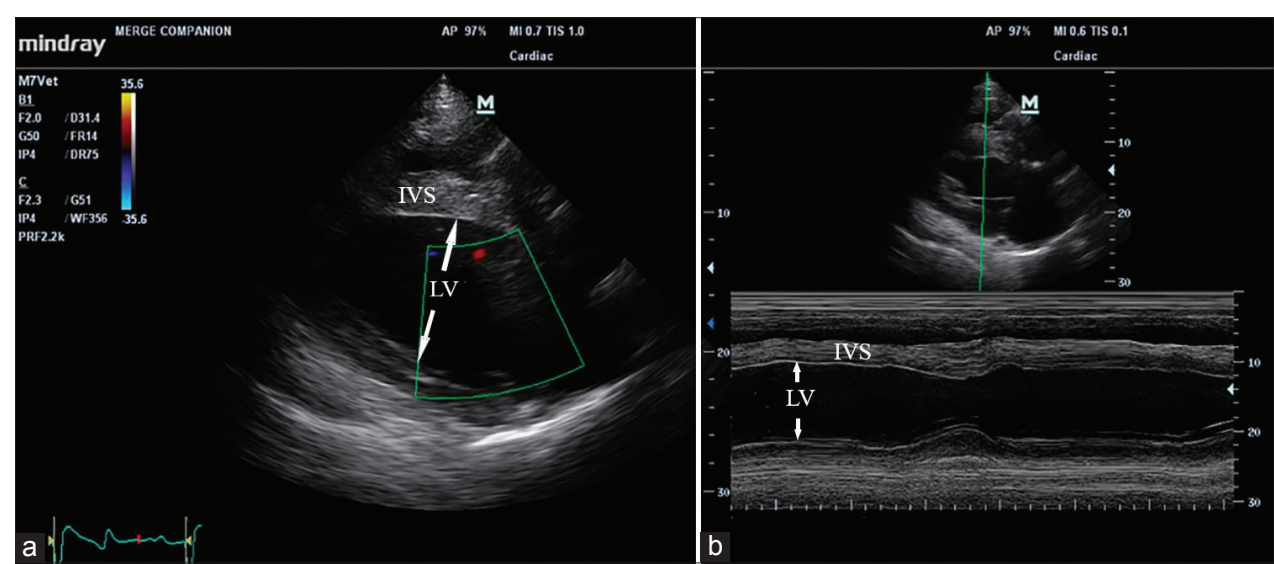

Figure-3: Echocardiographic of longitudinal image of heart (a) and M mode image of the left ventricle (b), arrow represented the left ventricular internal diameter; LV=left ventricle; IVS=Interventricular septum.

Table-4: Mean electrical axis parameters in two lead systems.

\begin{tabular}{|c|c|c|c|c|}
\hline \multirow[t]{2}{*}{ Lead system } & \multicolumn{2}{|c|}{ Base apex } & \multicolumn{2}{|c|}{ Modified precordial } \\
\hline & Control & Athlete & Control & Athlete \\
\hline $\begin{array}{l}\text { Vector } \\
\text { Quadrant }\end{array}$ & $\begin{array}{l}-42.09 \pm 49.46 \\
-16.36 \pm 56.69\end{array}$ & $\begin{array}{l}-18.00 \pm 51.14 \\
-16.36 \pm 56.69\end{array}$ & $\begin{array}{l}-117.82 \pm 3.95 \\
-106.36 \pm 4.72\end{array}$ & $\begin{array}{l}-119.18 \pm 4.95 \\
-105.00 \pm 4.77\end{array}$ \\
\hline
\end{tabular}

Data represented as mean \pm SEM

Table-5: Echocardiographic parameters.

\begin{tabular}{lcc}
\hline Parameters & Control & Athlete \\
\hline IVSd $(\mathrm{cm})$ & $2.75 \pm 0.12$ & $3.02 \pm 0.07$ \\
LVIDd $(\mathrm{cm})$ & $7.57 \pm 0.31^{*}$ & $8.50 \pm 0.33^{*}$ \\
LVPWd $(\mathrm{cm})$ & $2.98 \pm 0.14$ & $3.29 \pm 0.08$ \\
IVSs $(\mathrm{cm})$ & $3.52 \pm 0.1$ & $3.55 \pm 0.06$ \\
LVIDs $(\mathrm{cm})$ & $4.90 \pm 0.27$ & $5.65 \pm 0.39$ \\
LVPWs $(\mathrm{cm})$ & $3.51 \pm 0.17$ & $3.58 \pm 0.07$ \\
EF $(\%)$ & $61.40 \pm 2.85$ & $64.00 \pm 2.72$ \\
FS $(\%)$ & $34.09 \pm 2.07$ & $36.25 \pm 1.76$ \\
SV $(\mathrm{mL})$ & $194.93 \pm 17.54 *$ & $247.90 \pm 14.11^{*}$ \\
CO $(\mathrm{L} / \mathrm{min})$ & $8.11 \pm 0.72$ & $8.15 \pm 0.66$ \\
HR $(\mathrm{bpm})$ & $42.64 \pm 2.27 * *$ & $32.90 \pm 1.77 * *$ \\
LA/AO ratio & $1.19 \pm 0.02 * * * *$ & $1.26 \pm 0.04 * * * *$ \\
\hline
\end{tabular}

Data represented as mean $\pm \mathrm{SEM}, * \mathrm{p}<0.05$ compared with control group, $* * \mathrm{p}<0.01$ compared with control group,

$* * * \mathrm{p}<0.001$ compared with control group, $* * * * \mathrm{p}<0.0001$ compared with control group. IVSd: Diastolic

interventricular septum thickness, IVSs: Systolic interventricular septum thickness, LVIDd: Left ventricular end-diastolic diameter, LVIDs: Left ventricular end systolic diameter, LVPWd: Left ventricular wall diastolic thickness, LVPWs: Left ventricular wall systolic thickness. EF: The left ventricular ejection fraction, FS: Fractional shortening, SV: Stroke volume, CO: Cardiac output

two lead systems. The variability in the MEA parameters was found in this study (Table-4).

\section{Discussion}

This is the first study to assess the cardiac electrophysiological variables using a new lead system in Thai native crossbred horses. In the present study, the $\mathrm{R}$ wave amplitude was lower in the control group compared to the athletic group, which similar to the previous study that the $\mathrm{R}$ wave amplitude could be explained for the cardiac adaptation during athletic training $[14,15]$. The QT segment alterations suggest that the changes in cardiac repolarization and the cause of QT segment changes have not been specifically evaluated in the horse. However, across many other species, it serves as an indicator of life-threatening arrhythmias [16]. There was a very large difference in MEA between the two lead systems, which was similar to the results of the previous studies [17]. However, these results showed that the modified precordial lead system showed minor variation when compared with the results of the base apex lead systems. Echocardiography showed increased left atrium and left ventricular dimensions in athlete group, whereas left ventricular fractional shortening did not differ significantly between the groups. The changes of the left atrium and left ventricular internal diameter are consistent with what has been previously reported in athlete horses [18]. Although there was no significant difference regarding the left ventricular contraction function, stroke volume was increased and heart rate was decreased in athlete group (Table-5). These results might be indicated that exercise training had an influence on heart dimensions and were similar to the finding of a previous study that reported that athletes had larger hearts and larger stroke volumes than non-trained humans $[19,20]$. However, further study is required for applying the new modified precordial leads system in athletic horses.

\section{Conclusion}

In this study, a new lead system of cardiac electrophysiological evaluation was proposed and successfully applied in measuring the ECG signals in horses. From the experimental results, a modified precordial lead system is suitable for measuring electrocardiographic signal. The proposed system could provide a more reliable 
method than a base apex lead system and might be useful to apply in the health screening in the future.

\section{Authors' Contributions}

SP: Principle investigator, drafted and revised the manuscript. WC: A research coordinator, data collection and analysis. KK, NW, NN, WW and SS: Data collection and analysis. All authors read and approved the final manuscript.

\section{Acknowledgments}

The authors would like to thank Faculty of Veterinary Medicine, Kasetsart University, Thailand, for the financial support (The Funding for Special Problem Project, 2561).

\section{Competing Interests} interests.

The authors declare that they have no competing

\section{Publisher's Note}

Veterinary World remains neutral with regard to jurisdictional claims in published institutional affiliation.

\section{References}

1. De Backer, G., Ambrosioni, E. and Borch-Johnsen, K. (2004) European guidelines on cardiovascular disease prevention in clinical practice: Third Joint Task Force of European and other Societies on Cardiovascular Disease Prevention in clinical practice. Atherosclerosis, 171(1): 145-155.

2. Harmon, K.G., AsifI, M., Klossner, D. and Drezner, J.A. (2011) Incidence of sudden cardiac death in national collegiate athletic association athletes. Circulation, 123(15): 1594-1600.

3. Hong, L., Andersen, L.J., Graff, C., Vedel-Larsen, E., Wang, F., Struijk, J.J., Sogaard, P., Hansen, P.R., Yang, Y.Z., Christiansen, M., Toft, E. and Kanters, J.K. (2015) T-wave morphology analysis of competitive athletes. $J$. Electrocardiol., 48(1): 35-42.

4. Schmied, C. and Borjesson, M. (2014) Sudden cardiac death in athletes. J. Intern. Med., 275(2): 93-103.

5. Lyle, C. H., Uzal, F.A., McGorum, B.C., Aida, H., Blissitt, K.J., Case, J.T., Charles, J.T., Gardner, I., Horadagoda, N. and Kusano, K. (2011) Sudden death in racing thoroughbred horses: An international multicentre study of post mortem findings. Equine Vet. J., 43(3): 324-331.

6. Maron, B.J., Thompson, P.D., Ackerman, M.J., Balady, G., Berger, S., Cohen, D., Dimeff, R., Douglas, P.S., Glover, D.W., Hutter, A.M. Jr., Krauss, M.D., Maron, M.S., Mitten, M.J., Roberts, W.O. and Puffer, J.C. (2007) Recommendations and considerations related to preparticipation screening for cardiovascular abnormalities in competitive athletes: Update 2007: A scientific statement from the American Heart Association, nutrition, physical activity, and metabolism council. Circulation, 115(12): 1643-1655.

7. Hiraga, A. and Sugano, S. (2015) History of research in Japan on electrocardiography in the racehorse. J. Equine Sci., 26(1): 1-13.

8. Bond, R.R., Finlay, D.D., Nugent, C.D., Breen, C., Guldenring, D. and Daly, M.J. (2012) The effects of electrode misplacement on clinicians; interpretation of the standard 12-lead electrocardiogram. Eur. J. Intern. Med., 23(7): 610-615.

9. Buhl, R., Meldgaard, C. and Barbesgaard, L. (2010) Cardiac arrhythmias in clinically healthy showjumping horses. Equine Vet. J., 42(38): 196-201.

10. Slack, J., Boston, R.C., Soma, L.R. and Reef, V.B. (2015) Occurrence of cardiac arrhythmias in Standardbred racehorses. Equine Vet. J., 47(4): 398-404.

11. Cortez, D.L. and Schlegel, T.T. (2010) When deriving the spatial QRS-T angle from the 12-lead electrocardiogram, which transform is more Frank: Regression or inverse Dower. J. Electrocardiol., 43(4): 302-309.

12. Evans, D.L., Harris, R.C. and Snow, D.H. (1993) Correlation of the racing performance with blood lactate and heart rate after exercise in thoroughbred horses. Equine Vet. J., 25(5): 441-445.

13. Cravana, C., Medica, P., Ragonese, G. and Fazio, E. (2017) Influence of training and competitive sessions on peripheral b-endorphin levels in training show jumping horses. Vet. World, 10(1): 67e73.

14. Ayala, I., Gutierrez-Panizo, C., Benedito, J.L., Prieto, F. and Montes, A. (2000) Morphology and amplitude values of the electrocardiogram of Spanish-bred horses of different ages in the Dubois leads system. Vet. Res., 31(3): 347-354.

15. Mukherjee, J., Das, P.K., Ghosh, P.R., Banerjee, D., Sharma, T., Basak, D. and Sanyal, S. (2015) Electrocardiogram pattern of some exotic breeds of trained dogs: A variation study. Vet. World., 8(11): 1317-1320.

16. Zabel, M., Klingenheben, T., Franz, M.R. and Hohnloser, S.H. (1998) Assessment of QT dispersion for prediction of mortality or arrhythmic events after myocardial infarction: Results of a prospective, long-term follow-up study. Circulation, 97(25): 2543-2550.

17. Costa, C.F., Samesima, N. and Pastore, C.A. (2017) Cardiac mean electrical axis in thoroughbreds-standazrdization by the dubois lead positioning system. PLoS One, 12(1): 1-12.

18. Pluim, B.M., Zwinderman, A.H., Van Der Laarse, A. and Van Der Wall, E.E. (2000) The athlete's heart: A meta-analysis of cardiac structure and function. Circulation, 101(3): 336-344.

19. Amory, H., Votion, D.M., Fraipont, A., Goachet, A.G., Robert,C., Farnir, F. and Van Erck, E. (2010) Altered systolic left ventricular function in horses completing a long distance endurance race. Equine Vet. J. Suppl., 42(Suppl. 38): 216-219.

20. D'Andrea, A., Limongelli, G. and Caso, P. (2002) Association between left ventricular structure and cardiac performance during effort in two morphological forms of athlete's heart. Int. J. Cardiol., 86(2-3): 177-184. 